\title{
Explorando las interfaces comunicación- educación: el método Makárenko y los talleres de comunicación de los centros juveniles de la ciudad de Santos (Brasil)
}

\author{
Lucilene Cury y Andressa Carreira Luzirão Mouta \\ (Universidad de São Paulo) \\ Recibido: $11 / 7 / 2014$ \\ Aprobado: 22/8/2014
}

\begin{abstract}
Resumen: La obra del pedagogo ucraniano Antón Makárenko (1888-1939) es una referencia importante en el estudio de la organización de la escuela como un entorno colectivo. Mediante la transformación de jóvenes infractores en ciudadanos capaces de dirigir la sociedad y sus propias vidas, Makárenko probó que el trabajo colaborativo es capaz de moldear seres humanos solidarios y con responsabilidad social. Este artículo propone una reflexión sobre la perspectiva del autor, desde las actuales prácticas e interfaces comunicacióneducación con jóvenes brasileños que conviven con la violencia, las drogas y la pobreza en la ciudad de Santos (São Paulo, Brasil).
\end{abstract}

Palabras clave: Antón Makárenko / colectividad / comunicación-educación / cultura de paz / vulnerabilidad social

Exploring communication-education interfaces: Makarenko's method and communication workshops of youth centers in the city of Santos (Brazil)

Summary: The work of the Ukrainian educator Anton Makarenko (1888-1939) is an important reference in the organization of the school as a collective environment. By transforming offenders into citizens capable of running society and their own lives, proved that the collaborative work builds people with solidarity and social responsibility. This paper proposes a reflection on the author's perspective on current practices in communication-education interfaces, with young people who live with violence, drugs and poverty in SantosSP, Brazil.

Key words: Anton Makarenko / community / communication-education / culture of peace / social vulnerability 
La buena educación es aquella que valora a cada estudiante, aceptando sus diferencias y complaciéndose con ellas, invitándolo a ser parte de un proyecto colectivo a través del cual se aprende a mirar, a escuchar y a expresarse, con el apoyo de las nuevas plataformas.

María Teresa Quiroz Velasco

\section{Introducción}

$\mathrm{E}$ ste estudio, basado en el legado del pedagogo ucraniano Antón Semiónovich Makárenko (18881939), tiene como propósito señalar las contribuciones de su obra al desarrollo de prácticas e interfaces de comunicación-educación con adolescentes en situación de vulnerabilidad social en el municipio de Santos (costa de São Paulo, Brasil), quienes participan en talleres de comunicación realizados en centros juveniles de la Secretaría Municipal de Asistencia Social de esa localidad.

Conviviendo cotidianamente con fenómenos como la violencia, el tráfico de drogas y la pobreza - lo que caracteriza la desigualdad social de un país capitalista emergente como Brasil-, esos niños y niñas, en su mayoría, viven en una estructura familiar decadente; por eso, también sienten la falta de afecto y valores morales, muchas veces debido a las circunstancias que los rodean. Además, forman parte de una sociedad caracterizada por el consumo de bienes simbólicos y, como tal, son motivados a la adquisición de objetos, sobre todo al consumo de tecnología.

Es evidente que la juventud actual nació en la era posmoderna, marcada por la creciente evolución tecnológica y la convergencia de los medios de comunicación; por lo tanto, tiene un dominio natural de estos recursos. Es observando ese dominio y ese interés por las tecnologías que surge una luz para la posibilidad de cambios en la perspectiva social de esos adolescentes.

Aprovechar el potencial vinculado a la riqueza de las interfaces de dos campos de la ciencia - la comunicación y la educación- para modificar realidades no es una tarea fácil, porque al convivir con la violencia, las drogas y la pobreza, estos adolescentes se encuentran en una frágil línea que los lleva a la exclusión; en esta situación, pueden reproducir lo vivido por sus ascendientes y convertirse en ciudadanos sin perspectivas, sin esperanza de una transformación social y, con eso, estar a un paso de la marginalidad.

Robert Castel (1997), en La dinámica de procesos de la marginalidad: la vulnerabilidad y la desafiliación, comenta las situaciones marginales que aparecen al final del proceso de desvinculación con relación al trabajo y con relación a la inserción relacional. Se distinguen tres gradaciones para cada uno de ellos: trabajo inestable $=$ inserción relacional fuerte; trabajo precario $=$ fragilidad relacional; $\mathrm{y}$ ausencia de trabajo $=$ aislamiento social. Y explica que si se 
unen dos a dos esas gradaciones, tenemos tres zonas: la zona de integración (trabajo estable y fuerte inserción relacional, que siempre están juntos); la zona de vulnerabilidad (trabajo precario y fragilidad de apoyos relacionales); y la zona de marginalidad, que prefiero llamar zona de abandono para registrar nítidamente la amplitud del doble proceso de desafiliación: ausencia de trabajo y aislamiento relacional (Castel, 1997, p. 23).

Haciendo un recorte a la zona de vulnerabilidad, Castel afirma que ella ocupa una posición estratégica, pues es un espacio social de inestabilidad, en el que los sujetos están en una posición precaria en relación con el trabajo y frágil en su inserción relacional.

Por eso el riesgo de que caigan en la última zona, que aparece así, como el fin de un recorrido. Es la vulnerabilidad que alimenta la gran marginalidad o la desafiliación (Castel, 1997, p. 26).

A partir de esa frágil línea entre las zonas de vulnerabilidad y marginalidad, este estudio, que se centra en la observación de jóvenes en situación de exclusión, busca la perspectiva makarenkiana como referencia teórica en el desarrollo de prácticas pedagógicas, donde los recursos tecnológicos y las técnicas de comunicación, sobre todo del periodismo, son los instrumentos para el ejercicio de la ciudadanía, la posibilidad de expresión de esos jóvenes y el desarrollo de la llamada cultura de la paz.
El proceso de cambio de la perspectiva es, evidentemente, a mediano y largo plazo. Los resultados del trabajo de Makárenko evidencian que el cambio es gradual y se va cosechando día tras día con pequeñas transformaciones observadas en los alumnos. Es importante resaltar que fueron dieciséis años que el pedagogo estuvo al frente de las instituciones Centro Máximo Gorki (Poltava, 1920 a 1928) y la Comuna Dzerjinski (Járkov, 1927 a 1935) en Ucrania.

También es fundamental aclarar que este trabajo no consiste en utilizar su metodología con el objetivo de encontrar fórmulas para la obtención de resultados ya previstos, pero sí busca hacer de su obra una referencia a la experiencia positiva y que contribuya a la formación democrática de sujetos excluidos socialmente.

En la sociedad brasileña actual, al mismo tiempo que la violencia crece de manera exorbitante y es diariamente difundida por los medios de comunicación con bombardeos de mensajes de carácter negativo, se observa en las iniciativas aisladas un movimiento opuesto, que va en la búsqueda de un mundo mejor, con mejor calidad relacional, de solidaridad y de fe en el ser humano.

Es en esta perspectiva de fe en el hombre que Makárenko propuso, en el contexto de la Rusia revolucionaria, un trabajo de transformación de la estructura educacional. Empezó su epopeya desarrollando un proceso peda- 
gógico a largo plazo con adolescentes abandonados y menores infractores en el Centro Gorki, a lo que se sumó después el trabajo que llevó a cabo en la Comuna Dzerjinski para adolescentes abandonados.

Fue una época marcada por el zarismo, en la que el pedagogo, nacido en la ciudad de Bielo Polie, región de Járkov, Ucrania, el 1 de marzo de 1888, puso a prueba su psicología basada en la escuela como una colectividad. Hijo de una familia obrera - el padre trabajaba en el ferrocarril y la madre era ama de casa-, desde muy joven dio clases en escuelas primarias populares $y$, al terminar sus estudios en el Instituto Pedagógico de Poltava, en 1917, administró escuelas en Kriúkov y Poltava. Falleció de un ataque cardiaco a los 51 años en Moscú, el 1 de abril de 1939, año en que se inició la Segunda Guerra Mundial.

Bajo la influencia del escritor y humanista ruso Máximo Gorki, del filósofo alemán Karl Marx y del revolucionario y estadista ruso Vladímir Ilich Lenin, la pedagogía de Makárenko creció en los movimientos revolucionarios como una propuesta de construir un nuevo hombre, comprometido, llamado a la creación y al desarrollo de una sociedad revolucionaria. Bajo la influencia de Lenin, considera como necesaria la formación de este nuevo hombre, que sea trabajador y culto, que sepa comandar y subordinarse en una sociedad que tiene como finalidad abolir las diferencias de clases.
En el Centro Gorki, institución rural que atendía a niños y jóvenes, algunos de ellos eran huérfanos que habían vivido en la marginalidad, Makárenko y su equipo estaban relacionados con sujetos de las más variadas personalidades. Pero uno de los puntos básicos e importantes de su pensamiento de educación era ignorar las historias anteriores, el pasado de los educandos. $\mathrm{Su}$ finalidad no era crear etiquetas ni prejuicios de cada alumno.

Su pedagogía estaba enfocada en un modelo de escuela basado en la vida en grupo, la autogestión, el trabajo y la disciplina. De acuerdo con su forma de ver, la escuela es un espacio libre en contacto con la sociedad y la naturaleza, donde las decisiones son tomadas con la participación de alumnos y profesores. El sentido de colectividad debe prevalecer sobre lo individual, pues para Makárenko no podía existir educación si no es en colectividad. Para él, el grupo incentiva el desarrollo del individuo.

De acuerdo con su pensamiento,

la pedagogía socialista debe centrar su atención en la educación de la colectividad y ahí, sí, estará educando el nuevo carácter colectivista de cada niño en particular (Makárenko, 1985, p. 159).

Su método, lejos de predefiniciones de cada situación, tenía como principales factores metodológicos la confianza en la organización y en la autoridad; las formas participativas de 
gestión, las estrategias de democracia y la dirección colectiva; el trabajo colectivo; la moderación de elogios y demostraciones afectivas; y el repudio a la coerción física.

Los adolescentes practicaban ejercicios físicos; participaban en talleres; hacían trabajos manuales; tenían recreación, excursiones y lectura. Consideraban la agricultura como un medio de supervivencia y para mejorar la vida. Los talleres de profesionalización, las asambleas y las reuniones eran realizados para discutir situaciones, como por ejemplo: sobre un objeto robado, mejoras en el edificio del Centro, compra de materiales, limpieza y problemas personales. El primero y el último voto siempre eran de los alumnos.

Con mano dura y disciplina unida al afecto, comprensión y valorización, Makárenko logró índices positivos de mejora en el comportamiento de los jóvenes del Centro Gorki, que eran, al principio, rebeldes y complicados.

[...] yo defendía la creación de una colectividad vigorosa y, si fuera necesaria, severa y motivada, y solo sobre la colectividad es que apoyaba todas mis esperanzas (Makárenko, 1985, p. 153).
Allí, niños y niñas huérfanos y marginales fueron reeducados para asumir el comando de sus propias vidas y el de la sociedad. A lo largo del proceso de trabajo, los sujetos tenían conciencia de sus obligaciones, y desarrollaban iniciativa y autonomía.

En su ópera prima Poema pedagógico - y también en sus obras Libro para los padres y Banderas en las torres-, presenta las diferentes personalidades y el modo por el cual se desarrolla cada una de ellas en forma diversificada en el proceso de la autogestión del Centro Gorki. En la presentación del libro Poema pedagógico en Brasil, Tatiana Belinky ${ }^{1}$ resalta que Makárenko vio en cada adolescente un gran diapasón de posibilidades:

Makárenko supo forjar su «colectividad» en una amalgama de personas con mejores cualidades, jóvenes con voluntad de vivir, sentido de responsabilidad social y de honor individual, una prueba ejemplar de su principio educacional: exigir lo máximo de una persona y respetarla al máximo (1985, p. 9).

En el Centro Gorki, el conflicto principal fue la construcción de la co-

1 En 1985, la editora brasileña Tatiana Belinky hizo la traducción y escribió la presentación de la obra Poema pedagógico en Brasil. Ella nació en San Petersburgo, Rusia, en 1919, y cuando tenía 10 años su familia emigró a São Paulo. Con su esposo Julio Gouveia, adaptó obras infantiles para la televisión. Tatiana era poeta, traductora, dramaturga, y se consagró, especialmente por sus obras, a los niños. Sus libros y traducciones han recibido varios premios, como Nestlé, Jabutí y «Mejor para niños» de la Fundación Nacional del Libro Infantil y Juvenil (FNLIJ). Murió en 2013. 
lectividad y la transformación de los sujetos en ese proceso.

\section{Los destacamentos}

El pedagogo creó la propuesta de formación de grupos de trabajo -los llamados destacamentos-, que consistía en distribuir a los alumnos en los talleres y el trabajo agrícola, bajo la coordinación de un comandante: un joven designado por Makárenko en cada grupo, quien debía rendir cuentas del trabajo. Todos los comandantes constituían un órgano central de autogestión: el Consejo de la Colectividad (consejo de jefes de los destacamentos). El Centro Gorki era autosuficiente y la supervivencia de cada uno dependía del trabajo de todos; caso contrario, no habría comida ni condiciones de vivienda aceptables.

Pero fue con los llamados destacamentos mixtos - provisorios- que Makárenko logró cambios significativos en sus educandos: una colectividad unificada,

en la cual había diferenciación de trabajo y organización, democracia en la asamblea general, orden y subordinación de un compañero a otro, pero en la cual no se formó una aristocracia, una casta de comandantes (Makárenko 1985, p. 238).

En los destacamentos mixtos, los jóvenes cumplían tareas breves, puntuales y definidas no más de una semana, como arar un pedazo de tierra, remover el estiércol, sembrar, limpiar el material de la siembra y plantar papas en el campo. El destacamento mixto dejaba de existir cuando la tarea estaba terminada.

En el destacamento permanente, cada alumno tenía su comandante efectivo. En cambio, en los destacamentos mixtos, a cada nueva tarea le correspondía un nuevo comandante. El objetivo: que todos los jóvenes pudieran tener la experiencia de comando y de subordinación, cada cual con sus respectivas responsabilidades. Con este sistema cada educando participaba de las funciones de trabajo y también de la organización, lo que, para Makárenko, se hacía necesario en la educación (Makárenko, 1985, p. 241).

Con ese sistema de trabajo logró hacer que cada adolescente tuviera la experiencia de ser el comandante de un equipo y de estar subordinado a un comandante; de este modo, desarrollaba el respeto mutuo entre los sujetos $\mathrm{y}$, al mismo tiempo, creaba relaciones recíprocas provocadas por la subordinación entre iguales. Se desterraba así formas de comportamiento basadas en el autoritarismo y la explotación, a la vez que establecía nuevas formas de vida en relación.

\section{El uso de la tecnología}

La aceleración del flujo en la sociedad capitalista creó nuevos valores con la cultura del consumo. Caracterizan 
nuestro tiempo lo efímero, lo fugaz, la velocidad, el inmediatismo, lo superficial y la cantidad. En la velocidad de las máquinas, el joven de la generación posmoderna es capaz de aprender con rapidez, está inmerso en relaciones interactivas y hace uso de la tecnología con propiedad y dominio. Cada día surgen modelos innovadores de computadoras y teléfonos móviles con nuevas aplicaciones y configuraciones, con pantallas planas y sensibles al tacto; cámaras fotográficas y de video con efectos especiales, dispositivos modernos y fáciles de manejar, nuevas aplicaciones, plataformas y portales en internet.

Los medios de comunicación interactúan: los teléfonos móviles sacan fotografías, graban voces e imágenes, se conectan a la internet y a las redes sociales. En el espacio virtual es posible oír radio, ver un video, leer la versión en línea de un diario o una revista, así como descargar música y películas. No es raro que los telediarios exhiban imágenes capturadas por teléfonos móviles y cámaras de los telespectadores, mientras que en los diarios impresos es posible leer opiniones de internautas emitidas en redes sociales.

La posmodernidad es lo que Henry Jenkins (2009) llama «cultura de convergencia». La expresión define las transformaciones tecnológicas, mercadológicas, culturales y sociales del mundo global, en el que los consumidores son estimulados a hacer conexiones en medio de contenidos mediáticos dispersos e insisten en su papel de participantes. Para Jenkins, la era de la convergencia de los medios de comunicación permite modos de audiencias comunitarias, ya que son participativas e interactivas. El consumidor contemporáneo pasa a ser también productor de contenido, interactuando con instrumentos tecnológicos y utilizando sus posibilidades de interconexión.

Los ciudadanos comunes tienen hoy en día la posibilidad de crear productos mediáticos, hacer registros fotográficos y borrar aquellos que no fueron de su agrado. Pueden alterar una imagen; filmar a través de un teléfono móvil; editar un video a través de una computadora; crear un sitio o un blog en internet; colocar mensajes, videos y fotos en las redes sociales, entre otros.

En este contexto, Jenkins, para entender el nuevo paradigma mediático, relaciona los siguientes tres conceptos: convergencia de los medios de comunicación, cultura participativa $\mathrm{y}$, por último, inteligencia colectiva (Jenkins, 2009, p. 27).

En esa vasta gama de opciones que hace posible la participación, expresión y voz, está el sujeto de este estudio, el adolescente de clase social baja. Aunque insertado en un contexto de desigualdad, este joven nacido en el seno de la cultura tecnológica y digital - y también de consumo, como ya lo hemos mencionado- es un usuario asiduo de los recursos tecnológicos y de comunicación, sobre todo del teléfono móvil y la computadora, aun vi- 
viendo en una condición precaria, si la comparamos con las posibilidades financieras de un joven de las clases media y alta. Las redes sociales, especialmente Facebook, son su principal canal de comunicación e interacción con amigos y parientes.

Partiendo de la constatación de que el joven posmoderno tiene dominio nato de esos instrumentos y aparatos, el avance irreversible de las tecnologías puede ser un medio para que sujetos en desigualdad de condiciones puedan expresar su voz y cambiar sus perspectivas de vida, construyendo colectivamente, a partir de su realidad, una sociedad mejor. Según el educador argentino Daniel Prieto Castillo,

este tiempo nuestro, atravesado por el universo virtual, ha abierto una infinita trama de caminos para recuperar voces, sentires y experiencias de quienes hacemos a diario la educación en nuestros países (Prieto Castillo, 2010, p. 39).

Este desafío posibilita una importante contribución a las interfaces de los campos de la comunicación y de la educación, no solo en el mero sentido de usar los recursos mediáticos en la enseñanza, sino en cómo usarlos al servicio de la educación en un proceso participativo y dialógico entre educadores y educandos, con el objetivo de una educación para la vida, para una sociedad mejor.

En el texto Los objetivos de la educación (Luedemann, 2002), Makárenko menciona que no debemos hablar so- lamente de la formación profesional de la nueva generación o de la preparación para el mercado de trabajo, sino que deberíamos tener en cuenta la educación y un nuevo tipo de comportamiento societal, que resalte los trazos de la personalidad que son necesarios para la vida en sociedad en todos los ámbitos. Para él, la educación debe formar al hombre para la colectividad. En definitiva, ¿qué es la humanidad sino el conjunto de hombres que viven, conviven y dependen los unos de los otros?

\section{Grupo investigado}

Esta experiencia que aquí presentamos forma parte de una investigación para la adquisición del título en la Maestría de Ciencias de la Comunicación en el Programa de Posgraduación en Ciencias de la Comunicación (Ppgcom), de la Escuela de Comunicaciones y Artes de la Universidad de São Paulo (ECA/ USP). El Ppgcom está organizado en tres áreas de concentración: Teoría e Investigación en Comunicación, Estudios de los Medios y de la Producción Mediática y, por último, Interfaces Sociales de Comunicación; en esta área es donde se inscribe este estudio. La línea de investigación específica es comunicación y educación.

El estudio se inició en febrero del 2012 y el trabajo de campo el 2013. En cuanto a la colectividad, el foco de esta investigación estaba conformada por jóvenes de 14 a 18 años, pertenecientes 
a centros juveniles de dos regiones del municipio de Santos (São Paulo, Brasil), conocidas como Zona Noroeste y Zona Este. Estos centros juveniles forman parte de la Secretaría Municipal de Asistencia Social de la Alcaldía de Santos. Con una renta familiar de hasta tres sueldos mínimos (sueldo mínimo en Brasil: $\mathrm{R} \$ 724,00)$, ellos provienen principalmente de familias atendidas en Centros de Referencia de Asistencia Social (CRAS), que son unidades públicas de atención descentralizadas de la Política Nacional de Asistencia Social (PNAS) y localizadas en urbanizaciones o en comunidades de mayor índice de vulnerabilidad social.

El CRAS se caracteriza por ser una puerta de entrada para las familias y las personas a las acciones del Sistema Único de Asistencia Social (SUAS) en Brasil. De acuerdo con la Alcaldía de Santos, São Paulo, el CRAS recibe, acoge, atiende e identifica las situaciones que las familias están viviendo. Para ello, registra e informa sobre la red de servicios y beneficios sociales a la que tienen derecho y hace los seguimientos necesarios. También orienta y acompaña a la familia en su desarrollo.

Su principal servicio es el trabajo social con las familias por medio del Programa de Atención Integral a la Familia (PAIF), unido a la red de servicios de Protección Social Básica. Esa red está formada por centros comunitarios, centros de convivencia de ancianos y centros juveniles que prestan servicios de convivencia y fortalecimiento de vínculos familiares y comunitarios, lo que garantiza a los niños, adolescentes, jóvenes y familias experiencias para el desarrollo de sus capacidades. En ellos existe un espacio para jugar, para realizar talleres artísticos, culturales, deportivos, paseos, encuentros culturales e intercambio de saberes e informaciones. El CRAS también es responsable de los programas de transferencia de ingresos del gobierno federal, estatal y municipal a los brasileños.

Reiterando el enfoque de investigación, este estudio se ha desarrollado en los dos centros juveniles ya mencionados. En el 2013 se realizaron talleres de comunicación con los adolescentes; la frecuencia era de una vez a la semana en los dos locales, lo que en total daba cuatro horas semanales en cada una de las unidades.

A partir del 2014 participan de las actividades veinticinco adolescentes, todos estudiantes de escuelas públicas de la red estatal de enseñanza. Esa colectividad forma parte de un universo de 3623 jóvenes de 14 a 18 años que viven en Santos en aglomeraciones suburbanas. Según datos del Instituto Brasileño de Geografía y Estadística (IBGE) -Censo 2010, informaciones cedidas por la Secretaría Municipal de Asistencia social一, en Brasil cerca de dos millones de personas viven en áreas degradadas.

En la región de la Zona Este se encuentran las áreas denominadas Orilla de Playa, Intermediaria y Central Histórica. El centro juvenil que atien- 
de esa región está ubicado en la calle Joaquim Nabuco, n. ${ }^{\circ}$ 21, urbanización Vila Mathias. La demanda de jóvenes es predominantemente del área Central Histórica, formada por las urbanizaciones Vila Nueva, Paquetá/Puerto Paquetá, Valongo/Puerto Valongo, Centro, Vila Mathias y Outeriños. La mayoría pertenece a las urbanizaciones Centro, Villa Nueva y Paquetá.

El centro juvenil de la Zona Noroeste está situado en la avenida Brigadeiro Faria Lima s/n, urbanización Radio Clube, cercano a un área conocida como Dique da Vila Gilda, donde residen familias en palafitos amontonados, construidos a orillas del mangle, sobre el río Bugre. En este grupo predominan adolescentes de la urbanización Radio Clube.

\section{Región central}

En esta área es donde están concentradas las actividades del sector portuario y de comercio. La región central es el punto de inicio histórico de la población de la ciudad de Santos; alrededor de 1540, vivió la expansión y el auge del café y fue considerada el mayor puerto de América Latina. En el pasado, esta era la zona donde vivía la mayor parte de la población, sobre todo la aristocracia y la nobleza de Santos, hasta finales del siglo XIX y la primera mitad del siglo XX.

En Valongo, se concentraba el movimiento de carga y descarga de mer- cancías; es el área conocida hoy en día como Largo Marqués de Monte Alegre. Allí residían familias santistas de alto poder adquisitivo. Con el desarrollo del puerto, del comercio y del gran movimiento de carga local, esas familias acomodadas buscaron otras áreas para vivir, sobre todo áreas más cercanas a la orilla de la playa, debido al surgimiento de tranvías que transitaban hasta esta parte de la ciudad. Como explica André da Rocha Santos (2011, p. 553):

Sin embargo, todo el proceso histórico, económico y espacial ocurrido hasta entonces, será el momento de ruptura a partir del cual la región central de la ciudad consolidará su tradición portuaria y comercial y se convertirá con todas las transformaciones de finales del siglo XIX y principios del siglo XX, en una ciudad civilizada, saneada y moderna. Sin embargo, ese será también el momento en que el centro empezará a perder una de sus principales características, —cualquiera que seael lugar de vivienda de grupos sociales de alta renta. Las espaciosas casas de una planta y las de dos plantas de Paquetá y del Valongo son transformadas en poco tiempo en viviendas colectivas de estibadores, trabajadores del puerto y pequeño comercio. Las familias de mayor poder adquisitivo toman el «Caminho da Barra», esto es, el camino de la costa (playas) al que tenían acceso libre por el sistema de tranvías tirados por burros, por la orientación de las nuevas avenidas Ana Costa y Conselheiro Nébias y por los canales de Saturnino de Brito. A partir de ese 
periodo fue relegado al centro otra «función» en la estructuración económica y espacial de la ciudad.

En la zona de Largo Marqués de Monte de Alegre fue instalada la primera estación ferroviaria del Estado de São Paulo, la São Paulo Railway, que conectaba Santos a Jundiaí. Hasta la década de 1930, transportó café y mercancías, además de pasajeros. Fue desactivada en 1995 con el desarrollo ferroviario. Dentro del proceso de revitalización de la región central, hoy en día, el local es sede de la Secretaría Municipal de Turismo y cuenta con el Restaurante-Escuela Estación Bistró. También como parte del proceso de revitalización, fue inaugurado recientemente el Museo Pelé, y se construye la Unidad de Exploración y Producción de Gas y Petróleo de la Cuenca de Santos, de Petrobras.

La urbanización Paquetá también era un reducto de la alta sociedad santista. En el local está el cementerio de Paquetá, donde están sepultadas personalidades de la historia y la cultura de la ciudad, así como familias tradicionales y de la aristocracia. La urbanización Villa Nueva, donde está el tradicional Mercado Municipal, también fue una zona privilegiada de la ciudad. Según José G. Simões Jr. (1994, p. 11):

El deterioro de ciertas áreas urbanas es un fenómeno mundial, que desde mediados de la década de 1950, se ha intensificado en grandes ciudades mundiales, teniendo relación directa con las formas de producción y consumo. Características como el fuerte crecimiento de la población y la expansión física del entorno urbano, además de la inserción de la ciudad en un contexto económico industrial, establecieron nuevas formas de apropiación y valorización del suelo urbano, con reflejos en el mercado de bienes raíces, manifestándose más intensamente en las áreas centrales de esas ciudades.

Hoy en día es considerada un área de vulnerabilidad social. En ella interactúan personas adictas a las drogas, individuos que viven en la calle y prostitutas. Toda la región central es foco de inversiones del poder público, que incluyen la revitalización del área, así como la construcción de un centro cultural y deportivo, el Vehículo Liviano sobre Rieles y el sistema teleférico.

\section{Región Zona Noroeste}

La Zona Noroeste está formada por quince urbanizaciones, tiene 10,5 kilómetros cuadrados de extensión y más de 100000 habitantes. Originalmente, la región era un inmenso manglar atravesado por ríos que, en días de lluvia o marea alta, inundaban las viviendas. Gran parte de su población está compuesta por migrantes del norte, quienes vinieron a esta zona desde la ciudad a principios de la década de los años cincuenta para trabajar en el polo industrial de la ciudad de Cubatão, y terminaron ocupando terrenos sin infraestructura. Muchas viviendas fue- 
ron construidas en manglares, aplanados en el proceso de lotización.

En la región predominan actualmente casas de dos plantas (algunas de ladrillos, otras de madera) y edificios de tres pisos. En años recientes, la ascensión inmobiliaria en el municipio también llegó a esa región; se han construido cinco torres de apartamentos en la urbanización Castelo, cercanas a la Pasarela de Samba Dráusio da Cruz, donde, desde 2006, se realizan los desfiles de las escuelas de samba del municipio durante el carnaval brasileño.

Considerada como un área de gran vulnerabilidad social, la Zona Noroeste también es prioridad de una serie de inversiones del poder público en los sectores de vivienda, empleo, salud, medio ambiente y urbanización, cuyo objetivo es la solución de los principales problemas locales: inundaciones, construcciones desordenadas y los bajos ingresos de la población.
Las acciones integran el programa llamado «Santos Nuevos Tiempos», con el fin de eliminar definitivamente el problema de las inundaciones con la implementación del sistema de macrodrenaje, construir conjuntos habitacionales para los que viven en palafitos y realizar obras de urbanización e infraestructura.

Un diagnóstico socioterritorial de la ciudad de Santos, elaborado por la Secretaría Municipal de Asistencia Social de la alcaldía, aseguró que la región del Dique de Vila Gilda, en la Zona Noroeste, y los cerros son las áreas de mayor vulnerabilidad social. El estudio fue hecho por un sociólogo y un estadístico, con base en los datos del IBGE-2010, y servirá para que la Secretaría tome las acciones estratégicas para superar esas situaciones. Los siguientes mapas muestran las áreas, los barrios y las zonas de vulnerabilidad de la ciudad de Santos. 


\section{Áreas y barrios de la ciudad de Santos}

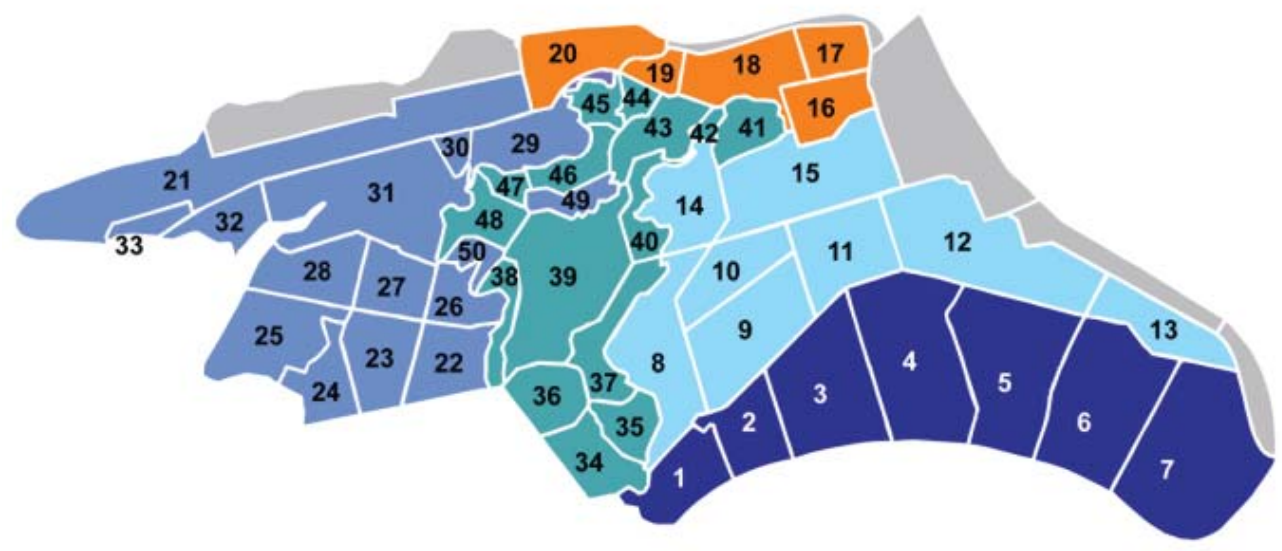

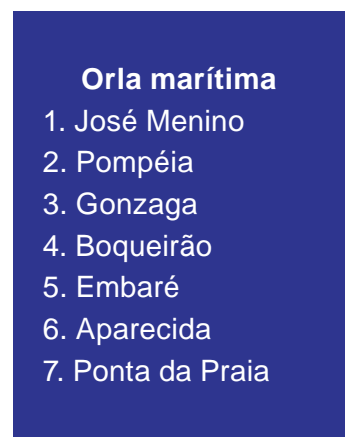

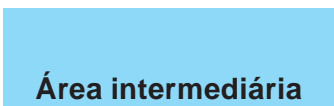

8. Marapé

9. Campo Grande

10. Vila Belmiro

11. Encruzilhada

12. Macuco

13. Estuário

14. Jabaquara

15. Vila Mathias

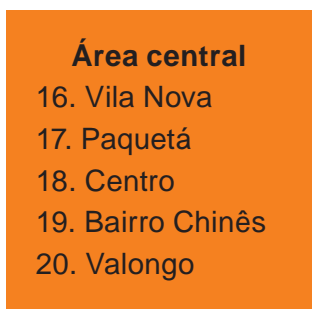

Zona noroeste

21. Alemoa

22. São Jorge

23. Areia Branca

24. Castelo

25. Rádio Clube

26. Caneleira

27. Santa Maria

28. Bom Retiro

29. Saboó

30. Vila Haddad

31. Chico de Paula

32. São Manoel

33. Piratininga

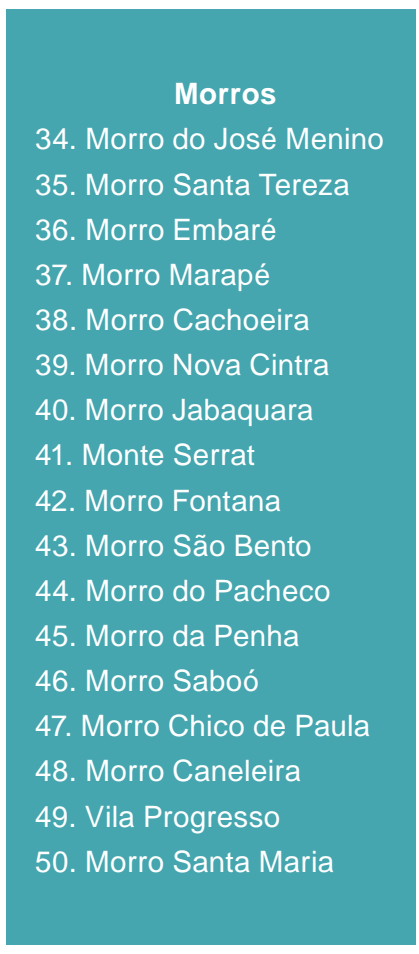

34. Morro do José Menino

35. Morro Santa Tereza

36. Morro Embaré

37. Morro Marapé

38. Morro Cachoeira

39. Morro Nova Cintra

40. Morro Jabaquara

41. Monte Serrat

42. Morro Fontana

43. Morro São Bento

44. Morro do Pacheco

45. Morro da Penha

46. Morro Saboć

47. Morro Chico de Paula

48. Morro Caneleira

49. Vila Progresso

50. Morro Santa Maria

Mapa suministrado por la Alcaldía de Santos. 


\section{Zonas de vulnerabilidad de la ciudad de Santos}

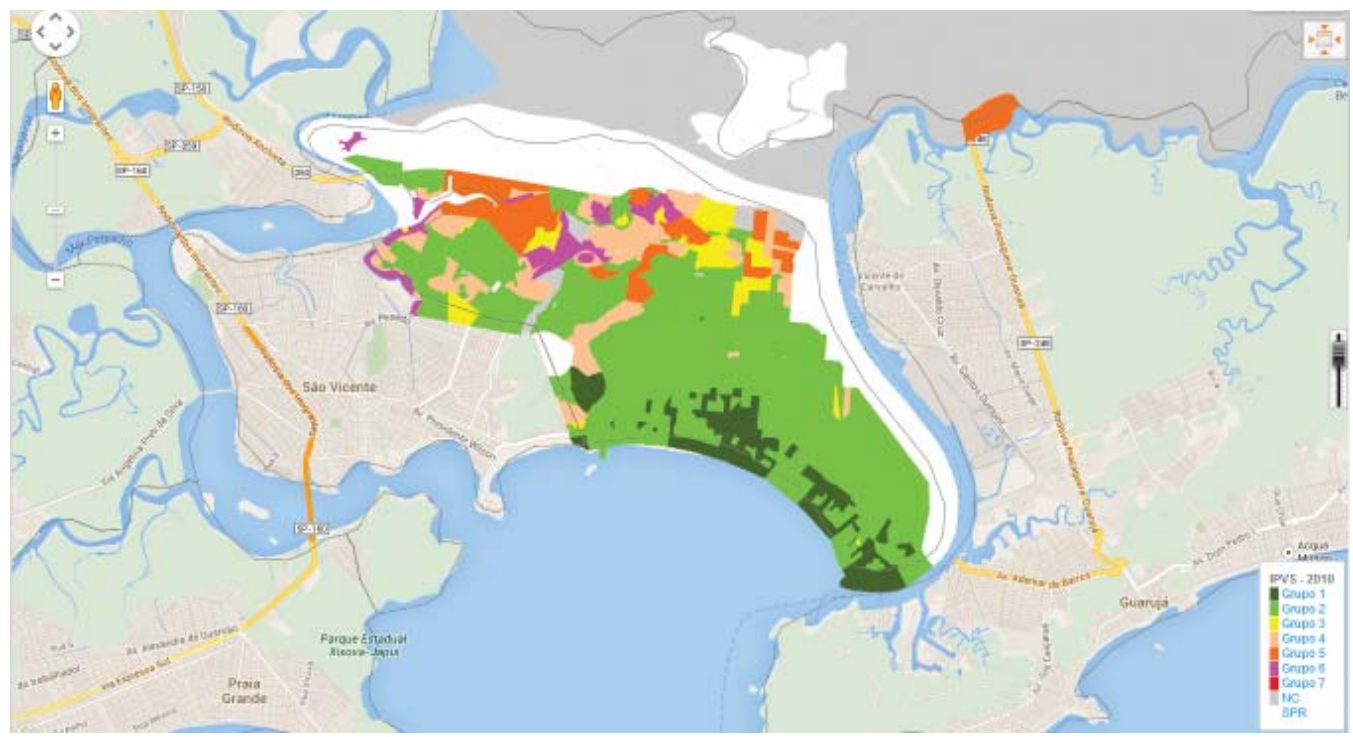

Mapa suministrado por la Alcaldía de Santos.

- En el grupo 1 (verde oscuro), había 46411 personas (11,1\% del total). El rendimiento nominal medio de los domiciliados era de $\mathrm{R} \$ 7,405, \mathrm{y}$ en el 1,0\% de ellos, los ingresos no pasaban de medio sueldo mínimo per cápita.

- En el grupo 2 (verde claro), había 291502 personas $(69,8 \%$ del total). El rendimiento nominal medio de los domiciliados era de $\mathrm{R} \$ 3,864$, y en el 3,6 \% de ellos, los ingresos no pasaban de medio sueldo mínimo per cápita.

- En el grupo 3 (amarillo), había 11 323 personas (2,7 \% del total). El rendimiento nominal medio de los domiciliados era de $\mathrm{R} \$ 1,927$, y en el $13,7 \%$ de ellos, los ingresos no pasaban de medio sueldo mínimo per cápita.

- En el grupo 4 (marrón claro), había 36366 personas (8,7 \% del total). El rendimiento nominal medio de los domiciliados era de $\mathrm{R} \$ 1,760$, y en el 20,0\% de ellos, los ingresos no pasaban de medio sueldo mínimo per cápita.

- En el grupo 5 (marrón oscuro), había 9855 personas (2,4\% del total). El rendimiento nominal medio de los domiciliados era de $\mathrm{R} \$ 1,512$, y 
en el 23,3\% de ellos, los ingresos no pasaban de medio sueldo mínimo per cápita.

- En el grupo 6 (violeta), había 22 433 personas $(5,4 \%$ del total). El rendimiento nominal medio de los domiciliados era de $\mathrm{R} \$ 1,185$, y en el $34,4 \%$ de ellos, los ingresos no pasaban de medio sueldo mínimo per cápita.

\section{El joven en las interfaces comunicación-educación}

En un momento en que la educación pública brasileña se encuentra en permanente desafío frente a los recursos tecnológicos y digitales - a lo cual se suma la falta de infraestructura y los bajos sueldos de los profesores, quienes se encuentran desmotivados en este escenario frente a las responsabilidades profesionales-, las interfaces de la comunicación-educación parecen llenar un vacío en la enseñanza no formal, sobre todo desde el punto de vista de la relación alumno-profesor, basada en la horizontalidad, la dialogicidad y el intercambio mutuo. El estudio que aquí se presenta tiene como foco la educación no formal, fuera de la escuela, de sujetos que estudian en la red pública estatal de enseñanza y que, en el contrapunto de las clases, participan de talleres de comunicación en los centros juveniles de la Secretaría Municipal de Asistencia Social, en Santos.
Con el grupo inicial, en el año 2013, se propuso la creación de un blog colectivo que integraba los dos grupos de zonas diferentes de la ciudad, llamados desde entonces Sucursales Periodísticas (Sucursal de la Zona Noroeste y Sucursal de la Zona Este), con la idea de «jugar a ser periodista». Para que ambos grupos pudieran interactuar, se abrió, además, una página virtual en la red social Facebook, a fin de que todos los participantes se conocieran, en un primer momento, por medio del espacio virtual.

Este trabajo de integración se apoyó en los estudios de campo acerca de las interfaces de comunicación-educación, siendo Mario Kaplún (2010) la mayor referencia. El autor afirma:

Bueno es, pues, que un sistema educativo sea grupal; pero mucho mejor aún que sea intergrupal. Tan dinamizador como promover la formación de grupos es proveer canales para que esos grupos se intercomuniquen los unos con los otros (2010, pp. 56 y 57).

Según Kaplún, un sistema intergrupal aumenta la visión de los involucrados, amplía su capacidad de expresión, promueve el intercambio y rompe barreras y prejuicios.

Por sugerencia de los dos grupos, la página virtual, cuya dirección es http:/www.falaserioblog.tumblr.com/, fue construida en la plataforma de blogs Tumblr, que permite a los usuarios publicar textos cortos, imágenes, 
videos, enlaces, citaciones y audio. La plataforma es una categoría intermedia entre el Wordpress, o Blogger y el Twitter. Los dos equipos sugirieron nombres para la página virtual y la elección final fue hecha por votación.

Es importante resaltar que el nombre elegido de la página, «Fala serio» (Habla en serio), se trata de una jerga, una variación lingüística utilizada por los jóvenes brasileños que, en este caso, también hace alusión al hecho de que esos jóvenes tienen como objetivo, con este producto de comunicación, expresar su pensamiento sobre los diferentes temas de su interés, o sea, esos jóvenes también quieren hablar en serio. El modelo de témplate también fue elegido colectivamente por los grupos a través del voto.

Los participantes crearon contenidos para el blog, que consistían en pequeñas noticias, indicaciones de películas ya vistas y abordadas en los talleres, registro de las actividades en las cuales participaron por medio de textos y fotos, entre otros. En el proceso, fue posible verificar la fascinación por la tecnología digital; sin embargo, ellos aún utilizan internet de forma superficial, tienen dificultad en la lectura e interpretación de textos y se sienten desalentados cuando es necesario leer contenidos que les parecen muy extensos.

El grupo actual empezó, en 2014, un proceso de aprendizaje sobre técnicas periodísticas, entre las cuales está la creación de lead de las noticias, el primer párrafo del texto que debe contestar a las preguntas: ¿quién?, ¿qué?, ¿cómo?, ¿dónde?, ¿cuándo? y ¿por qué? Asimismo, se les enseña la redacción de títulos, los criterios de cobertura en el periodismo, los modelos de textos periodísticos y las funciones existentes en la profesión.

El objetivo es ofrecer nociones de la práctica periodística para, a partir de allí, desarrollar un trabajo de producción de pequeñas noticias, con la finalidad de estimular, poco a poco, el hábito de leer y de escribir, comenzando por el texto corto, el propio lead del reportaje periodístico. Se pretende también hacer que escriban breves reflexiones y textos de opinión; textos de entrevistas elaborados por ellos, bien como registros fotográficos o pequeñas producciones audiovisuales con noticiarios producidos por los propios alumnos de los dos locales.

Cada centro juvenil tiene su equipo de jóvenes comunicadores - la Sucursal de la Zona Este y la Sucursal de la Zona Noroeste-, que desarrollan un trabajo de integración entre los grupos, el aprendizaje y la multiplicación de esta práctica entre ellos. El material será publicado en un sitio web que está en proceso de creación colectiva por los grupos: se trata de la plataforma gratuita Wiz.com.

El trabajo, utilizando los medios de comunicación, también tiene como objetivo contribuir a la formación de opinión y sentido crítico de los participantes. Kaplún (2010) señala que 
generar emisores activos ayuda a formar receptores críticos. Mencionando al educador Célestin Freinet, que llevó la idea del periódico escolar a una institución rural en las primeras décadas del siglo XX en Francia, Kaplún resalta que el pedagogo, al convertir a sus alumnos en periodistas, dejó que conociesen por dentro la producción de un medio de comunicación, desmitificándolo. Además, destaca el desarrollo del sentido crítico de los alumnos con la movilización de producir un periódico. Según Kaplún:

No es sorprendente, pues, que aprendieran a leer la otra Prensa - la profesional- con sentido crítico; ya sabían cómo un título puede impactar y predisponer al lector, cómo la manera de presentar una determinada información produce un determinado efecto de opinión, etc., porque lo habían experimentado por ellos mismos (2010, p. 59).

Aún citando a Freinet, el autor aborda el conocimiento como un producto social que es colectivo, cambia y se multiplica, o sea, comunica. Para él, aprender y comunicar son componentes de un mismo proceso cognitivo que deben ser recíprocos. «Educarse es involucrarse y participar en una red de múltiples interacciones comunicativas» (Kaplún, 2010, p. 54).

Para eso, el recorrido del trabajo sigue, gradualmente, en la capacitación de esos jóvenes. La metodología del trabajo desarrollada en los talleres, siempre orientada a la propuesta de trabajo en colectividad de Makárenko, en especial a su experiencia en los destacamentos mixtos, desde el inicio consistió en prácticas pedagógicas que aprovechan la esencia de la actividad profesional del periodismo. O sea, trabajo en equipo y distribución de tareas para la creación colectiva de un producto de comunicación, fruto de este proceso grupal, sea este un sitio web, un blog, un diario mural, un fanzine o un boletín informativo. Teniendo como base el substrato de la actividad periodística, se pretende con ello crear un colectivo unificado, un trabajo en grupo, de sociedades, colaboración e intercambio entre los sujetos.

En este sentido, en la distribución de tareas, cada joven es designado para una función específica - fotógrafo, reportero, jefe de reportaje-, de modo que todos puedan pasar por las diferentes funciones. Siendo así, el trabajo en equipo propicia mayor integración entre los sujetos; hace de ellos personas más solidarias y con espíritu de cooperación.

La finalidad es que comprendan que todos son importantes, esenciales, y que el desempeño y el trabajo de uno dependen del desempeño y el trabajo del otro. Para Makárenko, la colectividad

no es sencillamente un conjunto, un grupo de individuos en interacción. La colectividad es un complejo de individuos que tienen un objetivo determinado, están organizados y poseen organismos colectivos (Luedemann, 2002, p. 151). 
Entre las actividades de rutina ya citadas, también está la denominada «Giro de noticias», que consiste en una rueda de conversaciones en la que cada joven comparte con el grupo una noticia de la que tomó conocimiento a través de los medios de comunicación. Llama la atención el predominio del medio televisivo y del electrónico como aquellos donde los adolescentes encuentran y/o buscan más información. También prevalecen las noticias de carácter negativo, como criminalidad, violencia, tráfico de drogas y tragedias.

Insertada en esta rueda de conversaciones está la actividad llamada «Hechos-noticias». Se trata de situaciones y hechos que los jóvenes presenciaron en su vida cotidiana y que podrían convertir en noticia, dentro de los criterios de noticiabilidad enseñados, y que cada uno comparte con un compañero. Esta dinámica sobre los hechos ocurridos, en su mayoría, retratan violencia, banalidad, drogas y criminalidad, o sea, el universo en el que viven.

\section{Consideraciones finales}

En una era marcada por crímenes de gratuita extrañeza, caracterizada por la inversión de valores, las relaciones banalizadas (muchas veces motivadas por intereses económicos) y el consumo exacerbado, de competencia aguerrida e individualismo, volver a analizar la obra de Antón Makárenko se hace necesario, tal vez urgente. Incli- narse ante su obra en la contemporaneidad es traer a la vida la esperanza de días mejores, con más solidaridad y generosidad entre los seres humanos.

Tener su obra como referencia para este trabajo, que aquí no se cierra, sino, por el contrario, se esboza con jóvenes cuyas vidas están afectadas por su entorno, es creer en la posibilidad de una sociedad con más justicia social, donde la colectividad sobresalga al individualismo, para que el individualismo se fortalezca en la dignidad de su carácter. Que cada uno sea individualmente responsable por la vida en colectividad, con responsabilidad social y compromiso con la vida en sociedad y con la propia vida. En este recorrido, una de las principales dificultades encontradas es la creación de la colectividad. Se observa que, en el trabajo en equipo, lo individual aún prevalece y el oír al otro con respeto aún es una meta que debemos alcanzar.

Al mismo tiempo, el crecimiento del ciberespacio conlleva a un movimiento internacional de jóvenes ávidos por experimentar formas de comunicación diferentes de aquellas que los medios de comunicación clásicos proponen. Las transformaciones tecnológicas trajeron nuevas formas de relacionarse. Prieto Castillo sostiene: «Este tiempo nuestro, atravesado por el universo virtual, ha abierto una infinita trama de caminos para recuperar voces» (2010, p. 39). El autor afirma que las redes de aprendizaje ponen en juego elementos como participación, 
colaboración, activismo ciudadano, creación colectiva y alianzas voluntarias (Prieto, 2010, p. 38).

La evolución de la humanidad no se restringe al crecimiento frenético de la tecnología, sino que lo sobrepasa. Entonces, ¿por qué no usarla para tratar de cambiar realidades? A partir de la tecnología, las prácticas en las interfaces comunicación-educación parecen contribuir a la formación de sujetos excluidos socialmente, quienes, en la práctica lúdica del periodismo, puedan ejercer la ciudadanía, desarrollar sentido crítico, tener más autonomía e iniciativa y mostrar su voz. Que puedan aprender y multiplicar lo que asimilan, ampliar su repertorio cultural y sus perspectivas de vida para que se conviertan en personas con más cualidades y más personalidad, hombres más felices, capaces de aportar a la cultura de la convivencia y de la paz.

\section{Referencias}

Castel, R. (1997). A dinâmica do processo de marginalização: da vulnerabilidade a desfiliação. Caderno CRH. Recuperado de http://www. cadernocrh.ufba.br/viewissue. php?id=24

Jenkins, H. (2009). A cultura da convergência. São Paulo: Aleph.
Kaplún, M. (2010). Una pedagogía de la educación. En A. García Mantilla, J. Ferrés y Prats, \& R. Aparici (Eds.), Educomunicación: más allá del 2.0. Barcelona: Gedisa.

Luedemann, C. S. (2002). Anton Makarenko, vida e obra: a pedagogia na revolução. São Paulo: Expressão Popular.

Makárenko, A. S. (1985). Poema pedagógico. São Paulo: Brasiliense.

Prieto Castillo, D. (2010). Construir nuestra palabra de educadores. En A. García Mantilla, J. Ferrés y Prats, \& R. Aparici (Eds.), Educomunicación: más allá del 2.0. Barcelona: Gedisa Editorial.

Quiroz Velasco, M. T. (2012). Tecnologías digitales: para la educación y la comunicación. En L. Cury (Org.), Tecnologias digitais nas interfaces da comunicação/educação: desafios e perspectivas. Curitiba: Editora CRV.

Santos, A. R. (2011). Habitação precária e os cortiços da área central de Santos. Cadernos Metrópole, 13 (26), 549-571.

Simões Jr., J. G. (1994). Revitalização de centros urbanos. Polis. Recuperado de http://www.polis.org.br/uploads/ 1103/1103.pdf. 